\title{
Memoria, cultura manuscrita y oralidad en la cronistica franciscana portuguesa de la Edad Moderna
}

\author{
Federico Palomo[1]
}

\begin{abstract}
Resumen
Este artículo analiza el papel que los textos manuscritos e, incluso, la oralidad desempeñaron como instrumentos sobre los que asentaron determinadas formas de saber y de memoria entre los franciscanos, tanto en Portugal como en los contextos de su Imperio. Se consideran las estrategias memorísticas que los religiosos llevaron a cabo mediante la elaboración de crónicas e historias de las distintas provincias portuguesas de la Orden. Se analiza, por un lado, los elementos que determinaron la producción y circulación manuscrita de este género de escritos durante el siglo XVII, para, a continuación, examinar algunas de las prácticas eruditas que acompañaron la escritura de muchos de estos textos memorísticos.
\end{abstract}

Palabras clave: franciscanos; memoria; cultura manuscrita.

\section{Memória, cultura manuscrita e oralidade na cronistica franciscana portuguesa da Idade Moderna}

\section{Resumo}

Este artigo analisa o papel que os textos manuscritos e, até, a oralidade desempenharam enquanto instrumentos sobre os quais assentaram determinadas formas de saber e de memória entre os franciscanos, quer em Portugal quer nos espaços do Império. São assim consideradas as estratégias memorísticas que os religiosos desenvolveram através da elaboração de crónicas e histórias das várias províncias portuguesas da Ordem. São analisados, por um lado, os elementos que determinaram a produção e circulação manuscrita destes escritos ao longo do século XVII, para, a seguir, examinar algumas das práticas eruditas que acompanharam a escrita de muitos destes textos memorísticos.

Palavras-chave: franciscanos; memória; cultura manuscrita.

Memory, manuscript culture and orality in the portuguese franciscan chronicles during the Early Modern Times

\begin{abstract}
This article analyses the role played by manuscrits and even by orality as means of knowledge and memory among the Franciscans in Portugal and in the different contexts of the Portuguese Empire during the early modern times. It considers the strategies developed in order to build a Franciscan memory, namely through the writing of chronicles and histories related to the Portuguese Franciscan Provinces. First, it analyses some elements concerning those texts's production and their manuscript circulation during the 17 th century. Secondly, it examines the schorlaly practices which shaped the writing of chronicles among the Portuguese Franciscans. Keywords: Franciscans; memory; manuscript culture.

\section{Mémoire, culture manuscrite et l'oralité dans la chronistique franciscain portugaise de l'Époque Moderne}

\section{Résumé}

Cet article analyse le rôle des manuscrits et, même, de l'oralité en tant qu'instruments sur lesquels ont été construites certaines formes de savoir et de mémoire chez les franciscans du Portugal et des différents contextes de son Empire. A ce propos, on considère les stratégies de construction d'une mémoire franciscaine, développées à travers l'élaboration des chroniques et des histoires relatives aux différentes provinces portugaises de l'Ordre. On analyse d'abord les éléments qui ont determinés la production et la circulation manuscrite de ces textes pendant le XVIIe siècle. A suivre, on examine les pratiques érudites menées par les religieux dans lécriture des leurs chroniques.

Mots-clés: franciscains ; mémoire ; culture manuscrite. 

ntre los sujetos que se emplearon en el ejercicio de las misiones en el Portugal del siglo XVII, aquel que alcanzó mayor reputación y despertó las más poderosas adhesiones a sus prédicas fue el religioso Fr. António das Chagas, miembro singular de la Orden franciscana. Tras años dedicados al servicio de las armas y al cultivo de las letras, su entrada en religión, en 1663, lo condujo a desarrollar una intensa actividad misionera por todo el reino, que no sólo le ocupó de continuo hasta el final de sus días, como le valió la admiración de sus coetáneos y le granjeó una poderosa fama de hombre santo. Su particular empeño en este ministerio se materializó además en la fundación del que sería el primer seminario de la Orden seráfica dedicado específicamente a la formación de misioneros apostólicos, erigido en el antiguo convento de Nossa Senhora de Varatojo, en Torres Vedras, y enseguida transformado en cabeza de una nueva y espiritualmente pujante provincia de la congregación franciscana en Portugal, que se consagraría de lleno a la actividad de la misión (Pontes, 1955).

La notable personalidad de Chagas y su decidido afán apostólico no quedaron apenas reflejados en su acción sobre el terreno. Se tradujeron igualmente en la elaboración de un sinfín de escritos de tenor espiritual y doctrinal. A su muerte, ocurrida en 1682, no eran pocos los papeles salidos de su pluma que se encontraban dispersos por distintos conventos portugueses o en manos de monjas y particulares que habían tenido especial trato con el religioso. Así lo refería Miguel Godinho en el "Prólogo ao leitor" de uno de los varios volúmenes que reunió con los textos del fradinho (Chagas, 1690, preliminares sin paginar). A sus ocupaciones sobre los púlpitos, Chagas había sabido unir una singular constancia en la tarea de escribir, que no se concretó, sin embargo, en acabados sermones, de los que apenas dejó traza escrita en los cuadernos de sus apontados (Palomo, 2011). En realidad, se tradujo en numerosos textos devotos y en una extensa correspondencia espiritual que, constante, le ocupaba los tiempos no consagrados al ejercicio de la misión. Y, sin embargo, ninguno de los múltiples escritos que el religioso compuso fue dado a estampa mientras vivía, ni - como afirmaba una vez más Godinho - fue escrito "com intento de sahir à luz" (Chagas, 1688, t. II, preliminares sin paginar), como si el evitar las letras impresas no fuese sino expresión de una necesaria humildad religiosa o fruto de una obligada indiferencia hacia una ocupación tan vana y tan profana como, finalmente, era la de escribir. ${ }^{2}$

Esta aparente distancia que António das Chagas adoptó en relación con sus escritos y, en particular, con respecto a la circulación impresa de los mismos,

${ }^{2}$ Cabe subrayar la particular fortuna editorial que el religioso conocería después de su muerte. En los años inmediatos a su desaparición, Manuel Godinho, por encargo de lo superiores de la Orden, hizo imprimir las Cartas espirituais (Lisboa, 1684), los dos volúmenes de Obras espirituais (Lisboa, 1688) y los Sermoens genuinos (Lisboa, 1690). Se imprimió, además, otro volumen de sermones, titulado Escola de Penitència (Lisboa, 1687) y algún opúsculo, como Lágrimas, faíscas do amor divino (Lisboa, 1683). Los opúsculos con obras espirituales suyas y, sobre todo, con el Acto de contrición fueron numerosísimas (Pontes, 1950). Cabe destacar la traducción que los jesuitas hicieron de este texto al inglés, incluido en la edición de los The daily exercices of a Christian Life de Jerôme de Gonnelieu (París, 1684; Saint Omer, 1689). Agradezco a Fernando Bouza la indicación de estas dos ediciones. 
contrastaría con el uso que hizo de las prensas antes de su entrada en religión. ${ }^{3}$ Sería además un elemento que lo habría de distinguir de otros muchos misioneros que, en esos mismos años, no dudaron en recurrir a las prensas tipográficas para tratar de conferir perdurabilidad a sus acciones apostólicas. Puede que la actitud de Chagas no respondiese sino a una postura personal - de orden esencialmente espiritual - que le empujaba a huir de la honra y de la fama que le habría otorgado el dar a estampa a sus textos. Pero cabe igualmente conjeturar si su desapego hacia lo impreso no fue reflejo de otros factores, si esa abundante producción escrita que apenas circuló en copias de mano y un ejercicio de la predicación que asentó en la memoria y la capacidad para la improvisación, no fueron sino expresión de una cultura intelectual que, entre los franciscanos lusos, no se articuló necesariamente mediante el recurso sistemático a las formas impresas.

En este sentido, las próximas páginas se interrogan sobre el peso y el papel que los textos manuscritos e, incluso, la oralidad pudieron llegar a desempeñar como instrumentos sobre los que se conjugaron determinadas formas de saber y de memoria entre los franciscanos, tanto en Portugal como en los varios espacios de su Imperio. Para ello, daremos particular atención a las estrategias memorísticas que los religiosos movilizaron por medio de la elaboración de crónicas e historias, analizando, por un lado, varios de los elementos que caracterizaron la producción y circulación de este género de escritos dentro de la Orden durante el siglo XVII, para, a continuación, examinar algunas de las rutinas y prácticas eruditas que acompañaron la elaboración de muchos de estos textos memorísticos.

El estudio de los franciscanos y de su proyección política, religiosa, social y cultural en los espacios ibéricos de la Edad Moderna constituye un campo de análisis que sólo en los últimos años ha comenzado tímidamente a despertar el interés de los historiadores. Distintos problemas de orden metodológico e historiográfico han contribuido a situar tradicionalmente en un segundo plano el papel que la Orden seráfica desempeñó durante los siglos XVI-XVIII (Xavier, 2006). Si esto es notorio cuando se mira al mundo hispano, resulta aún más ostensible cuando se observa la producción historiográfica en torno a Portugal y a sus contextos imperiales. En parte, los problemas a este respecto derivan de la propia naturaleza fragmentaria de muchas de las fuentes disponibles y de los límites que ello conlleva, pero no dejan asimismo de ser consecuencia de algunas inercias historiográficas. El mundo franciscano se adivina a menudo como un espacio intrincado y no siempre fácil de aprehender, en el que, además de una compleja arquitectura institucional, convivían múltiples familias y sensibilidades religiosas (conventuales, observantes, capuchos, capuchinos), configurando una identidad múltiple, coral, que difícilmente cabe reducir a parámetros homogéneos (Buffon, 2013). Al mismo tiempo, la historiografía ha

3 Junto a una abundantísima producción poética manuscrita, el futuro Fr. António das Chagas, António Fonseca Soares, mandó imprimir el texto Mouram restaurado (Lisboa, 1658) y el Panegyrico ao excellentissimo Senhor Dom Antonio Luiz de Menezas, conde de Cantanhede (Lisboa, 1659). Cfr. Pontes (1950). 
privilegiado los estudios sobre los jesuitas y, en general, sobre aquellos institutos religiosos que, como la Compañía de Jesús, surgieron en los siglos XVI y XVII, siendo así considerados como expresión más genuina del catolicismo moderno. Frente a ellos, las "viejas" órdenes mendicantes y monásticas han sido vistas como meras congregaciones en decadencia, sujetas a lógicas heredadas de su pasado medieval.

Los desequilibrios en favor de la Compañía de Jesús se hacen aún más patentes cuando analizamos la cultura intelectual de los actores vinculados al clero altomoderno. No cabe negar la magnitud que alcanzó la producción escrita de los ignacianos, su capacidad para establecer mecanismos que permitiesen la circulación de la información a una escala sin precedentes, su habilidad para "inscribir" ciertos discursos y conformar determinadas memorias mediante el recurso sistemático a los textos (y, en particular, a los impresos), su destreza para hacer uso en cada momento de los medios más eficaces con los que difundir informaciones, conquistar almas e incluso forjar una imagen concreta de la propia Orden. En realidad, la dimensión escritora de la Compañía de Jesús y su vinculación a los espacios de producción del saber durante los siglos XVI-XVIII son elementos que han hecho de los religiosos jesuitas referentes de la "modernidad", convirtiéndolos muchas veces en paradigma de las prácticas que, en el mundo católico postridentino, definieron los contornos de la cultura escrita y religiosa (Giard, 1995; Fabre \& Romano, 1999; Chinchilla \& Romano, 2008; Betrán, 2010).

En realidad, una percepción más completa de las realidades plurales que conformaron el universo de la erudición y la escritura religiosa altomoderna, exige algunos matices. Requiere tomar en consideración el papel de otros actores que, como los franciscanos, tuvieron una proyección escrita y, sobre todo, impresa más reducida. Su empeño fue sin duda menor a la hora de dejar memoria y registro de su producción teológica, de sus prácticas espirituales, de sus empresas evangelizadoras por el mundo. Pero esto no quiere decir que su presencia en los varios contextos ibéricos y su protagonismo en el campo misionero no fuese muchas veces tanto o más importante que el alcanzado por los jesuitas (Xavier, 2008). Tampoco significa que fuesen meros actores circunstanciales en el campo intelectual, que sus respectivas actitudes con respecto al mundo del saber fuesen marginales o que, simplemente, no participasen del universo letrado. Puede que, en ocasiones, recurriesen sin más a prácticas y tradiciones eruditas diferentes - o no estrictamente idénticas - de las que observaron los miembros de la Compañía. A menudo, sin duda, siguieron rutinas comunicativas que no obedecían a lógicas tipográficas, pero que tampoco carecían de sentido en los propios contextos del mundo ibérico altomoderno. Conviene no olvidar que, lejos de articularse en torno a una cultura esencialmente impresa, las sociedades de este periodo siguieron recurriendo de forma indistinta a la oralidad, la imagen y la escritura de mano como formas de comunicación, conocimiento y memoria (Bouza, 1999; Bouza, 2001; Bouza, 2003). 


\section{Entre el obrar y el escribir: tópicos proemiales de una tradición cronística}

En el segundo de los tomos de la historia del convento de Brancanes, elaborada en 1741, Fr. João de Jesus Maria se lamentaba - excusándose ante sus eventuales lectores - de no poder dar noticia certera de todas las misiones que habían realizado los religiosos de dicho convento, después de que éste, siguiendo la senda de Varatojo, se hubiese transformado a finales del siglo XVII en seminario de misioneros apostólicos. La razón no era otra, como apuntaba el cronista, que la propia carencia de registros, relaciones y otras narrativas que, compuestas por los frailes que habían protagonizado dichas expediciones, diesen cuenta oportuna de las mismas. Fr. João no dejaba de subrayar que, en realidad, se habían dejado pasar "mais de sincoenta e tantos anos sem escrever huma só letra", lo que, en su opinión, no podía sino achacarse a la "humildade" de aquellos religiosos. Más inclinados, por tanto, a cultivar una virtud que les era tan cara, habían descuidado tareas profanas como la de escribir los hechos de sus misiones, sin reparar, con todo, "que as suas acções podião servir de exemplos aos vindouros".

En realidad, cuando el religioso invocaba el descuido o la indiferencia que habría caracterizado siempre a la Orden seráfica y a sus miembros a la hora de conservar por escrito su memoria, no hacía sino recoger y reproducir un argumento que empleó de un modo casi sistemático la mayoría de los cronistas e historiadores portugueses de la congregación franciscana, al menos, desde mediados del siglo XVII. Ese alegado desinterés, de hecho, adquiriría una naturaleza tópica - casi retórica - en los proemios y discursos al lector con los que abrían las crónicas impresas de las varias provincias. Todo apunta a que la idea tenía bastante de imagen construida y que, sólo en parte, respondía a una realidad caracterizada efectivamente por la penuria de testimonios escritos sobre el pasado fransciscano y, en especial, sobre el de sus miembros más distinguidos.

La imagen, no obstante, parecía abundar en la percepción de un universo franciscano caracterizado por cierto "anti-intelectualismo", ajeno a todo interés por las cosas de letras, alejado de la erudición y de las prácticas escritas. Esta visión - que la propia historiografía ha contribuido a perpetuar - se desvanece ante determinados indicios que, en realidad, dibujan un universo de una densidad intelectual considerable. Como se ha subrayado recientemente, el simple análisis de algunas bibliotecas pertenecientes a los conventos portugueses de la Orden permite delinear un perfil bastante diferente (Xavier \& Županov, 2015, p. 164-169). En el contexto metropolitano, reunieron, de hecho, algunas de las más importantes colecciones de libros vinculadas a las instituciones eclesiásticas. Sin olvidar la que se constituyó en el convento de Mafra, fundado bajo el patrocinio de Juan V de Portugal, librerías como las de

${ }^{4}$ Arquivo Nacional da Torre do Tombo (ANTT). Fr. João de Jesus Maria. Chronica de Brancanes. Tomo $2^{\circ}$ Missões mais notaveis, que tem feito este santo Seminario com os cazos, que succederão nellas dignos de memoria postos em seus lugares [...]. Anno 1741, Livraria, ms. 852, f. 8. 
Santo António de Varatojo, en Torres Vedras, ${ }^{5}$ São Francisco de Xabregas, en Lisboa, ${ }^{6}$ el Seminario de Brancanes ${ }^{7}$ o Santa Maria da Arrábida (Rocha, 1994) fueron acervos de particular envergadura, algunos de los cuales hoy constituyen núcleos importantes de los fondos de la Biblioteca Nacional de Lisboa. En realidad, tanto estas colecciones como las más modestas que pertenecieron a comunidades franciscanas menos numerosas (Carvalho, 1998; Carvalho, 2005) no se distinguían en términos generales de aquellas que encontramos en otras congregaciones religiosas da la época (Campos, 2015). ${ }^{8}$ En el fondo, los franciscanos poseían un horizonte de referencias intelectuales y de lecturas que, más allá de tradiciones espirituales y teológicas propias, de orientaciones identitarias, de gustos personales, no era muy diferente del que podían tener agustinos, jesuitas, dominicos o carmelitas. Algo parecido sucedía en los contextos coloniales. La información sobre las bibliotecas de la Orden en Asia y la América lusa es escasa y fragmentaria. ${ }^{9}$ No obstante, permite adivinar colecciones razonablemente nutridas de tratados de teología dogmática y moral, exégesis, patrística, sermonaria, historia eclesiástica, filosofía... Una reconstrucción más "virtual", sobre la base de las prácticas letradas y las lecturas empleadas en sus escritos, no sólo muestra rutinas intelectuales semejantes a las del mundo metropolitano. Pone asimismo de manifiesto un universo textual que, en buena medida, compartían con sus correligionarios del Viejo Mundo, pero al que, con frecuencia, se añadían otras tradiciones eruditas y un conocimiento local (religioso, natural, medicinal, etc.), fruto de la propia experiencia o de un saber previamente acumulado in situ por otros actores (Xavier, 2011). Esta implicación en el mundo del saber, por lo demás, se haría aún más explícita desde finales del siglo XVII y a lo largo del siglo XVIII. Al menos en los contextos de la monarquía portuguesa, los franciscanos comenzaron entonces a tener mayor presencia en círculos eruditos y academias, alcanzando además mayor fortuna tipográfica (Kantor, 2004; Palomo, 2014).

No obstante, es indiscutible que los frailes menores gozaron de menor visibilidad impresa. En parte, fue consecuencia de una práctica de la escritura aparentemente menos intensa. Nunca desarrollaron, por ejemplo, un sistema de intercambio epistolar semejante al que establecieron los jesuitas, y su discreta implicación en el ámbito académico tampoco les permitió destacar en géneros como la tratadística teológica, la filosofía o los cánones. Sólo la sermonaria y los textos de devoción parecen haber tenido mayor relevancia y una traducción

\footnotetext{
5 Biblioteca Nacional de Portugal (BNP). Catálogo da Biblioteca do Seminário e Convento de Varatojo. Códs. 11670-11673. Accesible en: <http://purl.pt/27293>. Consultado el 19 abr. 2016.

${ }^{6}$ BNP. Index Geral da Livraria do Convento de S. Francisco de Xabregas... Anno de 1809, cód. 8383. Accesible en: <http://purl.pt/27269>. Consultado el 19 abr. 2016.

${ }^{7}$ ANTT. Cathalogo Alphabetico dos Livros da Bibliotheca do Real Seminario de Nossa Senhora dos Anjos do Brancanes. Livraria, ms. 1898. Accesible en: <http://digitarq.arquivos.pt/viewer?id=4248783>. Consultado el 19 abr. 2016.

${ }^{8}$ En ocasiones, las diferencias derivaban más de las funciones - formativas/apostólicas - que asumía cada establecimiento religioso que de su adscripción a una determinada orden (Carvalho, 1998, p. XXIII).

9 Para el Imperio asiático portugués, se conoce el inventario del convento de Santo António de Tana, de 1725 (Xavier, 2011; Buescu, 2001). En el caso de la América portuguesa, se ha hecho una reconstrucción parcial de las bibliotecas de Salvador, Olinda, Paraíba e Igarassú (Almeida, 2012, v. II, p. 481-532).
} 
impresa más significativa durante los siglos XVI y XVII. En resumen, frente a la producción de jesuitas, oratorianos o dominicos, los religiosos de la Orden seráfica escribieron posiblemente menos, pero, sobre todo, recurrieron con menor intensidad a las prensas tipográficas, cultivando además géneros que hoy — quizás - se nos antojan menores y de reducido lustre.

\section{Los franciscanos poseían un horizonte de referencias intelectuales y de lecturas que no era muy diferente del que tenían agustinos o jesuitas}

En este sentido, no cabe menospreciar el papel que pudieron llegar a tener los manuscritos en las prácticas letradas de estos religiosos, propiciando una circulación más restringida y controlada de textos cuya naturaleza, por otro lado, los hacía más abiertos y, por tanto, susceptibles de ser reescritos (Bouza, 2011). En cierta medida, la producción de escritos ad vivum explica que el acervo de obras que ha llegado hasta nosotros represente apenas una parte de lo que, en realidad, elaboraron los franciscanos durante la Edad Moderna, contribuyendo - una vez más - a cristalizar la visión de aparente desapego intelectual que se les ha atribuido. Sin embargo, las Bibliotecas de Barbosa Machado, Lucas Wadding o Juan de San Antonio recogen numerosas indicaciones de textos que compusieron los religiosos de la Orden seráfica, que circularon en copias de mano y que, entretanto, se han perdido. Entre los múltiples escritos que dichos catálogos recogen, de hecho, no faltan los memoriales, las historias, las crónicas de las distintas provincias y conventos portugueses de la Orden, que se elaboraron durante el siglo XVII y aún en la centuria de 1700, y que, frente a los volúmenes impresos, mantuvieron su carácter de textos manuscritos, sirviendo esencialmente para consumo de las propias comunidades franciscanas y de sus cronistas y escritores.

\section{La memoria en copias de mano: crónicas franciscanas en el siglo XVII}

Frente a las prácticas de la Compañía de Jesús, que recurrió indistintamente a cartas, relaciones, vidas e historias como instrumentos sobre los que construir la memoria escrita de la Orden, los franciscanos se apoyaron principalmente en géneros como el cronístico y el hagiográfico. Ciertamente, los frailes menores no dejaron de recurrir a misivas y relaciones misioneras, pero parece indiscutible que no lo hicieron con la misma intensidad que los religiosos ignacianos, ni de un modo tan sistemático y reglado. Sus usos de las cartas fueron aparentemente más episódicos e irregulares, careciendo, en todo caso, del particular sentido memorístico que, junto a otras funciones, llegaron a tener entre los jesuitas (Palomo, 2005). La crónica, como es conocido, habría de desempeñar a lo largo de la época moderna una función esencial para la mayoría de las 
órdenes religiosas - también para los jesuitas - como instrumento privilegiado a la hora de inscribir, favorecer y celebrar un pasado que se quería ejemplar y edificante, capaz de articular modelos de conducta y de reforzar la identidad espiritual y religiosa de las comunidades a las que se dirigía (Carvalho, 2001a; Atienza, 2012). El relato cronístico, no obstante, podía llegar a tener una dimensión relativamente codificada en lo que a sus formas se refiere y su elaboración estuvo a menudo determinada por criterios de orden institucional que dejaban poco espacio para la autonomía y para una escritura al margen de las estructuras de la propia congregación. Capítulos y superiores designaban a menudo a los "cronistas" de la Orden o de la provincia, movilizaban recursos documentales y llegaban a supervisar una tarea que, en ocasiones, obedecía a motivaciones concretas - de orden político, espiritual, etc. —, viéndose además sujeta a formas de aprobación y censura internas.

La elaboración y edición de las Crónicas da Ordem dos Frades Menores de Fr. Marcos de Lisboa durante la segunda mitad del siglo XVI son clara expresión de tales extremos. El religioso portugués asumió las funciones de cronista de la Orden franciscana en torno a los años de 1550, recibiendo el encargo del entonces ministro general, Fr. André da Ínsua, de componer la crónica general de toda la congregación seráfica y, en particular, de su instituto observante. El trabajo que acometió Fr. Marcos se tradujo en una extensa obra en tres volúmenes que salieron a la luz impresos, en Lisboa y en Salamanca, entre 1557 y 1570, alcanzando una considerable recepción en toda la Europa católica. No obstante, la obra tampoco dejó de encontrar algunas dificultades y la edición de la tercera parte se vio sometida al expurgo de los examinadores de la congregación, habiéndose eliminado algunos episodios que se entendieron apócrifos y, por tanto, menos aptos a la edificación (Carvalho, 2001b, p. 23; Sanz Hermida, 2002).

La empresa de Fr. Marcos de Lisboa abrió la senda a nuevos proyectos editoriales que, desde finales del siglo XVI y a lo largo de la centuria de 1600, vendrían a conformar la memoria de la Orden en su conjunto, desde el De origine Seraphicae Religionis de Francisco Gonzaga (Roma, 1587) al Orbis Seraphicus de De Gubernatis (Lyon, 1682-1685), pasando por los Annales Minorum de Lucas Wadding (Lyon, 1625-1648; Roma, 1654) o la Hierarchia Francescana de Diego da Lequile (Roma, 1664) (Buffon, 2011). El empeño impresor que se mostró desde las instancias generales del instituto franciscano, sin embargo, no encontró un eco similar en el contexto portugués de ese mismo periodo, siendo escasas las crónicas e historias que, centradas en algunas de las provincias que articulaban la presencia de los frailes menores en Portugal y en sus dominios, se dieron entonces a estampa. En realidad, el grueso de la cronística franciscana sólo alcanzaría mayor expresión tipográfica dentro del mundo portugués durante el siglo XVIII, cuando, bajo el patrocinio de las distintas provincias y de las Órdenes Terceras, se mandó elaborar e imprimir en torno a una treintena de volúmenes, entre los cuales, los textos de Fr. Fernando da Soledade y Fr. Jerónimo de Belém sobre las provincias observantes de Portugal y de los 
Algarves (Soledade, 1705-1721; Belém, 1750-1758), el tomo de Fr. Martinho do Amor de Deus en torno a la provincia de Santo António (Amor de Deus, 1740), el de Fr. António da Piedade sobre los frailes arrábidos (Piedade, 1728) o la crónica que compuso Fr. António de Santa Maria Jaboatão acerca de la provincia de Santo António do Brasil (Jaboatão, 1761).

Hasta entonces y a lo largo del Seiscientos, circularían impresos los dos volúmenes de la História Seráfica (Lisboa, 1656 y 1666) que compuso Fr. Manuel da Esperança, relativos a la provincia de Portugal (Fardilha, 2001), la Chronica da Provincia da Piedade de Fr. Manuel de Monforte (Lisboa, 1696) y el Vergel de Plantas, e Flores da Provincia da Madre de Deos (Lisboa, 1690) que elaboró el capucho Fr. Jacinto de Deus, sobre la presencia de los religiosos descalzos en la India (Faria, 2011). En realidad, una obra como la de Esperança - que incidía sobre la mayor y más antigua provincia portuguesa de la Orden — situaba en un plano de igualdad a los franciscanos con respecto a otros institutos religiosos portugueses que, en esos mismos años, compusieron y mandaron asimismo imprimir sus respectivas crónicas provinciales. A la Chronica de Cister de Fr. Bernardo de Brito (Lisboa, 1602), se sumaron los tres primeros tomos de la Historia de São Domingos particular do Reyno de Portugal, elaborados por Fr. Luís de Sousa (Lisboa, 1623, 1662 y 1678), o los dos volúmenes de la Chronica da Companha de Iesu na Provincia de Portugal, del jesuita Baltasar Teles (Lisboa, 1645-1647). Pero si dominicos y, sobre todo, jesuitas supieron además publicitar sus respectivas empresas misioneras en el Índico y en el Atlántico por medio de cartas, relaciones, vidas y crónicas impresas, el relato de la presencia franciscana en la India, Ceilán, China o las costas de Guinea, Brasil y Maranhão no alcanzó ni por asomo idéntica proyección tipográfica durante el siglo XVII. Al mencionado Vergel de Plantas de Fr. Jacinto de Deus, apenas se añadieron cerca de una veintena de impresos elaborados por religiosos vinculados a las misiones en las distintas partes del Imperio, sin que, por otro lado, se tratase en general de textos de carácter memorístico. ${ }^{10} \mathrm{Ni}$ siquiera entre los franciscanos del reino, la dimensión misionera de la Orden tuvo una particular traducción impresa. Monforte, en su crónica sobre la provincia de la Piedad, dedicó apenas algunos capítulos a los religiosos que habían pasado a la India en el siglo XVI, dando origen a la provincia de Madre de Deus (Monforte, 1696, p. 399-428). Sólo en 1705, Fr. Fernando da Soledade dedicó todo el libro V del tercer tomo da la História Seráfica a la presencia de los frailes menores en los contextos asiáticos (Soledade, 1705-1721, t. III, p. 485-613).

\footnotetext{
${ }^{10}$ De los franciscanos vinculados a la India, salieron impresos durante el siglo XVII el Itinerario da India de Fr. Gaspar de São Bernardino (Lisboa, 1611), la Relação Defensiva dos Filhos da India oriental (Barcelona, 1640), la Vida Evangelica, e Apostolica de los frayles Menores (Barcelona, 1641) y la Apologia al Libro de la Vida Evangelica (París, 1642) de Fr. Miguel da Purificação, así como el Tribunal da Provincia da Madre de Deus (Lisboa, 1670), el Escudo dos cavaleiros das Ordens Militares (Lisboa, 1670), la Brachilogia de Princepes (Lisboa, 1671), el Caminho dos Frades Menores para a Vida eterna (Lisboa, 1689) y el Vergel de Plantas (Lisboa, 1690) de Fr. Jacinto de Deus. Entre los impresos de los franciscanos de la América portuguesa, cabe apenas señalar los sermones sueltos de Fr. Agostinho da Conceição (Barbosa Machado, 1741-1767, t. l, p. 63) y los textos devotos de Fr. António do Rosario: Feyra Mistica de Lisboa (Lisboa, 1691), Carta de Marear (Lisboa, 1698), Sortes de Santo António (Lisboa, 1701) y Frutas do Brasil (Lisboa, 1702).
} 
Los contornos de esta escasa fortuna editorial - y el contraste con la extraordinaria visibilidad tipográfica de los jesuitas - se harían patentes en las propias vicisitudes que rodearon la circulación de un texto como la Conquista espiritual do Oriente que, compuesto por Fr. Paulo da Trindade en torno a 1630, quedó como la principal elaboración memorística de los franciscanos de la India. El escrito surgió con la intención de contrarrestar la visión que el jesuita Gian-Pietro Maffei había delineado en sus Historiarum Indicarum Libri XVI (Florencia, 1588). Elaborada originalmente por encargo del cardenal-rey D. Enrique, la obra del italiano vinculó los hechos de los portugueses con la acción de los religiosos jesuitas, presentados como actores principales de la misión evangelizadora que le cabía a la corona (Andretta, 2004). Frente a la imagen trazada por Maffei de un mundo asiático ganado al catolicismo por los ignacianos, la crónica de Trindade reivindicaría el papel y la primacía de los frailes menores (Lopes, 1962; Biedermann, 2014; Xavier \& Zupanov, 2015, p. 70-190). No obstante, a diferencia del texto de Maffei, la Conquista de Trindade permaneció manuscrita hasta el siglo XX, a pesar de los intentos de su correligionario, Fr. Miguel da Purificação, por darlo a estampa durante los años que estuvo en Europa como procurador de la provincia de São Tomé da Índia. En realidad, el episodio de la (fallida) impresión del texto de Trindade, así como las ediciones barcelonesas de otros textos que Purificação había llevado consigo (Xavier, 2014), no dejan de ser expresivas de las dificultades que enfrentaron y los fracasos que cosecharon los religiosos franciscanos - sobre todo, aquellos vinculados a las provincias asiáticas y americanas - a la hora de adentrarse en el universo editorial. La ausencia de tipografías en los espacios coloniales luso-americanos o, como en Asia, su presencia discontinua constituía una dificultad añadida, ya que obligaba a recurrir a las prensas del Viejo Mundo, debiendo enviar allí los manuscritos y someterlos a las instancias de aprobación y censura metropolitanas, antes de iniciar un proceso de impresión que difícilmente se podía controlar. Entre los franciscanos, hubo además una dimensión económica que no debió ser una cuestión menor, especialmente en una Orden que tenía en la pobreza una de sus señas de identidad. El propio Purificação se lamentaba de este extremo y de las consecuencias que tenía a la hora de conseguir que circulasen impresos muchos de los escritos destinados a la evangelización que habían elaborado sus correligionarios en la India (Xavier, 2014, p. 109). No faltaron los religiosos que recurrieron a patrocinadores locales. En Pernambuco, Fr. António do Rosário obtuvo el apoyo de D. Francisco de Sousa, señor de ingenio, y de Simão Ribeiro Ribas, miembro de la elite mercantil de Recife, a la hora de costear respectivamente la impresión de su Carta de Marear (Lisboa, 1698) y de sus Frutas do Brasil (Lisboa, 1702) (Palomo, 2016). Años después, ya durante la primera mitad del siglo XVIII, Fr. Apolinário da Conceição acudió asimismo al patrocinio de algunos sujetos de Rio y Minas Gerais para la edición de varios de los volúmenes que hizo imprimir en Lisboa entre 1733 y 1744 (Palomo, 2014, p. 124-132). Con todo, no debió ser éste un problema que apenas afectase a los franciscanos vinculados a los 
diferentes espacios del Imperio. También en el reino, debió ser un factor de peso - entre otros que cabría considerar - a la hora de recurrir a las prensas tipográficas, permitiendo en parte explicar una producción relativamente modesta de impresos a lo largo del siglo XVII, hecha mayoritariamente de tratados de devoción y sermones sueltos, como ya se ha apuntado. ${ }^{11}$

\section{No cabe menospreciar el papel que desempeñaron los manuscritos en las prácticas letradas de los franciscanos, propiciando una circulación más controlada de los textos}

En el ámbito concreto de la cronística, la práctica inexistencia de impresos que narrasen las actividades de observantes y capuchos en los distintos contextos del imperio portugués, no significó - como acabamos de ver - la ausencia de una producción manuscrita que, en ocasiones, manifestó cierta precocidad. Como es bien conocido, quien fuera autor de la primera Historia de la América portuguesa, Fr. Vicente do Salvador, dejó también escrito un cartapacio, hoy desaparecido, con una Chronica da Custódia do Brasil que había elaborado en torno a 1618 (Barbosa Machado, 1741-1767, t. 3, p. 770; Oliveira, 2008). Poco después, Fr. Manuel da Ilha compuso otro memorial, Divi Antonii Brasiliae Custodiae enerratio seu relatio (1621), en el que, a lo largo de 87 folios, daba cuenta asimismo de la presencia franciscana en la América portuguesa. Elaborado para la Historia de la Orden que entonces preparaba Fr. Benigno da Genova, Ilha - que no tenía un conocimiento directo del Brasil — se sirvió del De Origine Seraphicae Religionis de Gonzaga, de la propia Chronica de Fr. Vicente y de las notas que había dejado Fr. Leornardo de Jesús, antiguo custodio del Brasil (Ilha, 1975). Ya en el último cuarto del siglo XVII, Fr. Cristóvão da Madre de Deus compuso un manuscrito titulado Cuidado contra o tempo en el que, al parecer, reunió informaciones sobre el Brasil desde la llegada de los portugueses y la presencia franciscana. En 1683, siendo provincial, compuso además un nuevo memorial, conocido como Cartório da Provincia da Immaculada Conceição do Brasil, en el que, en diez capítulos, "recopilou a Origem desta Provincia con todos os Breves, e varias noticias pertencentes a ella atè o tempo que a escreveo" (Barbosa Machado, 1741-1767, t. I, p. 582-583). ${ }^{12}$ De ellos dio noticia y se sirvió, ya en el siglo XVIII, Fr. Apolinário da Conceição para la composición de varios de sus escritos y, entre ellos, del Epitome do que em breve

"A falta de un estudio específico sobre la cuestión, seguimos los datos obtenidos a través de las búsquedas realizadas en la base de datos bibliográfica Porbase.

${ }^{12}$ Félix Lopes no atribuye obra alguna a este religioso, aunque confirma la existencia de un libro titulado Cartulário a modo de memorial de la provincia, conservado en el archivo de la Provincia de la Inmaculada Concepción de Brasil (Lopes, 1997, p. 155). 
suma contem a Provincia de N. S. da Conceição da cidade de Rio de Janeiro no Estado do Brasil, que, a modo de crónica de su provincia, compuso en $1730 .^{13}$

Un carácter muy distinto tuvo la Historia Natural, e Moral do Maranhão en cuatro volúmenes que dejó lista para su impresión Fr. Cristóvão de Lisboa, en torno a 1650. Perdida en 1755, de ella formaba parte el códice conocido como História dos Animaes e arvores do Maranhão, en el que Fr. Cristóvão incluyo 163 láminas de dibujos con distintas especies animales y vegetales autóctonas (Walter, 2000). La Historia - que, en principio, había de comprender tanto la descripción de la naturaleza marañense, como noticia de la empresa apostólica franciscana, inauguró una producción relativamente amplia de escritos - en su mayoría, desaparecidos - que los franciscanos implicados en la evangelización del Maranhão elaboraron entre los siglos XVII y XVIII. En ellos, articularon distintos saberes directamente relacionados con su experiencia del Imperio. Junto a varias relaciones de carácter memorístico (Lopes, 1997, p. 157-160), dejaron manuscritas descripciones geográficas e, incluso, algún tratado de contornos etnográficos, como el que compuso Fr. Francisco do Rosário (Barbosa Machado, 1741-1767, t. II, p. 246). Pero, sobre todo, elaboraron un buen número de vocabularios, gramáticas, catecismos y obras devotas en lenguas indígenas, como el Catecismo em língua brasílica del propio Fr. Francisco do Rosário o los múltiples textos en la lengua de los maraunûs y de los aroás de Fr. João de Jesus y Fr. Mateus de Jesus Maria (Barbosa Machado, 1741-1767, t. II, p. 246; t. IV, p. 180, 253).

Los religiosos de la provincia de São Tomé en la India, así como los capuchos de la provincia de Madre de Deus, no dejaron de realizar asimismo algún esfuerzo memorístico por medio de varios textos que circularon también manuscritos. Antes incluso de que Paulo da Trindade escribiese su Conquista espiritual, ya Fr. Gaspar de Lisboa y, en especial, Fr. Francisco Negrão habían elaborado sendos escritos sobre la presencia y acciones de los frailes menores en los espacios del Índico desde la llegada de los portugueses. El memorial de Fr. Gaspar se compuso en torno a 1584, a instancias de Fr. Francisco Gonzaga, con vista a utilizarlo en la composición de su De Originis Seraphicae Ordinis. El texto de Negrão obedeció a razones similares, pero constituyó un auténtico relato cronístico de la provincia de São Tomé, del cual - perdido - se conservan algunas noticias sobre su elaboración, su circulación manuscrita y su utilización en textos como el del propio Paulo da Trindade (Barbosa Machado, 1741-1767, t. II, p 214). A parte del ya referido Vergel de Plantas del capucho Fr. Jacinto de Deus y de las memorias que Fr. Miguel da Purificação incluyó puntualmente en sus impresos (vd. supra nota 10), son escasas las noticias que tenemos de otros textos memorísticos del siglo XVII, como si la Conquista Espiritual de Trindade hubiese otorgado un carácter definitivo a la memoria sobre la presencia franciscana en el Asia portuguesa. Eso no quiere decir que,

${ }^{13}$ Una copia manuscrita y autógrafa del Epítome se conserva en la Biblioteca Nacional do Brasil (BNB), Rio de Janeiro. Manuscritos, I-1, 1, 7. Una edición moderna, a cargo de Fr. Gentil Titton, en Revista do Instituto Histórico Geográfico do Brasil, n. 296, p. 68-165, 1972. 
al igual que sus hermanos americanos, los religiosos - tanto observantes como capuchos - no cultivasen otros géneros escritos, fruto de su experiencia sobre el terreno. Desde la Taprobana del propio Negrão (sólo impresa en 1713) a los textos en konkaní - en su mayoría desaparecidos — de Fr. Amador de Sant'Anna ${ }^{14}$ y Fr. Gaspar de São Miguel o las anónimas Viagens pela India, todos ponen de manifiesto una cierta vitalidad - entre las décadas centrales del siglo XVII y el final de la centuria — en la construcción de saberes geográficos, lingüísticos o de carácter etnográfico y, con ello, en la elaboración de una suerte de orientalismo católico (Xavier \& Županov, 2015, p. 158-201).

Al margen de la importancia que la producción manuscrita asumió entre los frailes menores presentes en los espacios coloniales, las copias de mano no dejaron de ser también un elemento central en la conformación y difusión, dentro de las comunidades franciscanas del reino, de las narrativas que habrían de fijar la memoria de la Orden en Portugal, de su provincias y conventos. Un simple vistazo al inventario de fuentes narrativas que, en su día, elaboró Félix Lopes, permite advertir el volumen considerable de escritos de carácter memorístico que salieron de las plumas de los religiosos franciscanos durante el siglo XVII (y aún durante la centuria de 1700), ya fuese bajo la forma de crónicas, historias o memoriales más generales, relativos a las distintas provincias portuguesas, ya fuese como historias particulares de los conventos o como vidas de algunos sujetos que se significaron por sus virtudes y santidad (Lopes, 1997).

Entre los religiosos más prolíficos, junto a los frailes de la provincia de Arrábida, se encontraron los observantes de la provincia de los Algarves. Como ya se ha indicado, su crónica impresa, elaborada por Fr. Jerónimo de Belém, vio la luz en la década de 1750. Antes, sin embargo, contó con varios memoriales que, por encargo de los superiores de la Orden, fueron sucesivamente redactados en el siglo XVII y durante la primera mitad de la centuria de 1700 . Una parte significativa de estos textos, de hecho, sirvió de base para la crónica del propio Belém, que reunió y ordenó, numerándolos, los memoriales de Fr. Rodrigo de São Tiago (1616), ${ }^{15}$ Fr. João de São Francisco (1647), ${ }^{16}$ Fr. João de Santo Estévão (1680) ${ }^{17}$ y de Fr. João dos Reis, compuesto en las primeras décadas de $1700 .{ }^{18}$ No serían éstas las únicas memorias o relaciones que se elaboraron en el seno de la provincia franciscana, ni los únicos textos, ciertamente, de los que hizo uso Jerónimo de Belém para la composición de su crónica. En todo caso, la lógica que, ordenándolas, les impuso el religioso franciscano nos

\footnotetext{
${ }_{14}$ Una copia manuscrita de su Flors santorum. Historia das vidas, e feitos heroicos, e obras insignes dos santos... reduzido em lingoa canarim (Goa, 1607) aparece referida en Cabaton, 1912, § 779 [Bibliothèque Nationale de France, Ms. Indien, 137].

${ }^{15}$ ANTT. Rodrigo de São Tiago. Memorial da Santa Prove dos Algarves da Ordem Serafica. [Tomo 10] Memorial Primeiro... No anno de 1615 e 1616. [1616], OFM. Prov. Algarves. Provincia, liv. 22.

${ }^{16}$ ANTT. João de São Francisco. Relação Memorauel da Santa Prouincia dos Algarues. Memorial Segundo escripto em 1647. Livraria, ms. 408.

${ }_{17}$ ANTT. Origo Prouinciae Algaruiorum Erectiones Conuentum Fratrum et Monialium. Compendiumque rerum notabilium... Memorial 3o da Santa Provincia dos Algarves, por Fr. João de Sto. Estevão Leitor Jubilado. Anno de 1680. Livraria, ms. 525.

18 ANTT. Daniel dos Reis. Memorias da Santa Prouincia dos Algarues da Ordem Serafica. Anno de 1746. Memorial quarto. Livraria, mss. 1911-1912.
} 
permite hoy advertir con mayor claridad la propia secuencia y los vínculos que se establecieron entre esos cuatro manuscritos, consintiendo al mismo tiempo el interrogarse sobre algunas de las prácticas eruditas que rodearon la elaboración de los escritos cronísticos.

\section{Revolver papeles y escuchar a religiosos de buenas partes}

La composición sobre el papel de estas obras - el escribir crónicas - solía conllevar todo un trabajo de recopilación de noticias, documentos y libros que, a menudo, se extendía en el tiempo, obligando en ocasiones a que el religioso incumbido de esta tarea peregrinase por los distintos conventos de la Orden, en los que examinaba y trasladaba toda suerte de papeles y volúmenes conservados en sus respectivos archivos y librerías. El propio Manuel da Esperança afirmaba que, durante varios años, había visitado todos los cartórios de su provincia, así como la mayoría de los que pertenecían a las otras congregaciones franciscanas del reino; había buscado en los archivos de las catedrales de Coímbra, Guarda y Lamego, en el de la colegiata de Guimarães y en los de los monasterios de Alcobaça y Santa Cruz de Coímbra, sin dejar además de consultar los archivos regios da la Mesa da Consciência y Torre do Tombo, así como los acervos municipales de Lisboa y Oporto (Esperança, 1656-1666, t. 1, preliminares sin foliar).

Peor fortuna tuvo Fr. António de Santa Maria Jaboatão a la hora de reunir papeles que le sirviesen para elaborar su Orbe Serafico Novo Brasilico (Lisboa, 1761). Como Esperança, también él recorrió los varios conventos de la provincia de Santo António do Brasil. No obstante, lo que encontró - aseguraba había sido tan poco y el modo en que se conservaban los archivos era tal, "que mais nos servia de embaraço ao discurso, do que de norte, e luz para a historia" (Jaboatão, 1761, Antiloquio, preliminares sin paginar). En realidad, el acopio de noticias y documentos no siempre implicaba la realización de periplos como el que Jaboatão aparentemente realizó. Con frecuencia, se movilizaban las propias redes institucionales de la Orden. Los superiores podían ordenar que se elaborasen ex profeso escritos con noticias de esta o aquella provincia, de este o aquel convento. En ocasiones, simplemente establecían cuestionarios por medio de los cuales recabar de forma relativamente homogénea determinadas informaciones de las distintas casas y conventos de la provincia, como el que, en torno a 1738, envió impreso el provincial de los Algarves. En él se pedía una descripción de cada convento, su emplazamiento, cuándo había sido fundado y por quién, qué imágenes poseía y si eran milagrosas, qué reliquias y cómo habían llegado al convento, las capillas que había en la iglesia y a quién estaban dedicadas, las obligaciones de misas que había y quiénes las habían instituido. Se requería asimismo noticias de los religiosos o religiosas que habían fallecido con fama de virtud, de los papeles que había en el archivo y, en particular, de los pleitos, cartas regias, breves, etc. De muchos de ellos, se 
pedía además copia o, en su caso, el envío al cronista de la provincia del documento original para que procediese a su traslado. ${ }^{19}$

El juntar papeles, sin embargo, pasaba a menudo por el recurso a terceros - religiosos e, incluso, particulares - a los que se pedía que reuniesen puntuales informaciones, acudiendo ellos mismos a los cartórios y librerías existentes en los lugares donde residían. La tela de contactos que el cronista debía tejer solía ser relativamente extensa, pudiendo envolver a sujetos de otros reinos o, incluso, de las Indias. En este sentido, el religioso participaba en ocasiones de una singular república literaria de dimensiones planetarias, cuya configuración se vio incentivada por la propia naturaleza que encerraron las redes de casas, conventos y misiones de las distintas órdenes religiosas involucradas en la evangelización, contribuyendo a la circulación de la información entre las cuatro partes del mundo (Brockey, 2012; Hernández, 2013). En 1638, el carmelita descalzo Fr. João de Cristo dejó testimonio de una praxis que, en realidad, fue común entre historiadores sagrados y profanos (Bouza, 2001, p. 248-261; Montcher, 2015). El religioso escribía entonces una misiva en la que daba cuenta a su interlocutor del cómo, dónde y a quién se debía pedir papeles para elaborar - como se le había encargado - una Historia de las misiones carmelitas en Asia, que, aparentemente, debía ser complemento a la Historia General Profetica de la Orden del Carmen de Fr. Francisco de Santa María (Madrid, 1630). ${ }^{20}$ Fr. João no sólo había sido Vicario General de los carmelitas en la India y procurador en Roma de su provincia, como, de vuelta a Portugal, dedicaba sus días a escribir vidas de religiosos y otras memorias históricas de su Orden (Barbosa Machado, 1741-1767, t. II, p. 636). Todo ello lo convertía en personaje indicado para la composición de la Historia que ahora se pretendía elaborar. Él mismo reconocía como una de sus ventajas la de ser portugués, ya que para tratar de las partes de Asia, entendía ser necesario el "tener dellas mucha noticia". Sus correligionarios en Castilla podían encontrar más dificultades, pues - como afirmaba - "ni tratan con los que por allá an viuido, ni con los que allá viuen se cartean, ni traen entre manos los libros que de aquellos reinos tratan". Tan importante como acceder a los volúmenes que recogían noticias sobre Persia y la India, era el corresponderse con quienes podían de primera mano suministrar informaciones y, sobre todo, traslados de escritos. En este sentido, su experiencia anterior en el Índico ayudaba. Al fin y al cabo, su tarea - como afirmaba - pasaba por "escribir a la Jndia, Magor, Arabia, Percia y Palestina", tanto "a los Religiosos nuestros Portuguezes amigos mios", como "a seglares mis deudos que en aquel estado de la Jndia residen", además de acudir, en Lisboa, a "personas graues" con el fin de que "por medio de otras que en el Oriente tienen, me saquen papeles de los nuestros". ${ }^{21}$

\footnotetext{
19 ANTT. Daniel dos Reis. Memorias da Santa Prouincia dos Algarues da Ordem Serafica. Anno de 1746. Memorial quarto. Livraria, ms. 1911, f. 351

${ }^{20}$ Archivo Histórico Nacional (AHN). Madrid. Carta de Fr. João de Cristo (Lisboa, 6 nov. 1638), Ministerio de Asuntos Exteriores. Obra Pía, legajo 4, sin foliar. Agradezco a Fernando Bouza su generosidad al darme a conocer este manuscrito.

${ }^{21}$ Ibidem.
} 
En su percepción del trabajo que se le había encomendado, entendía que quien como él debía escribir historia, tenía obligación de "todos los rincones [...] reuoluer, por uer si halla coza que le sirua, que muchas vezes un papelico da vida y alma a grandes relaciones". En este sentido, Fr. João no sólo mostraba capacidad para movilizar correspondientes en los lugares más remotos del Imperio, como ponía de manifiesto un conocimiento apurado de los lugares a los que acudir en busca de papeles y de las dificultades que, en ocasiones, entrañaba. En relación con las misiones carmelitas en Asia, apuntaba en primer lugar a los propios correligionarios de Italia, de los que se decía que tenían más de siete volúmenes en latín "de las coças de la religión”. Y, aunque no sabía si en ellos se trataba en particular de la misiones, tenía por seguro que existían relaciones que se enviaban anualmente al general de la Orden y que, necesariamente, se conservaban en Roma. Junto a los papeles de Italia, difíciles de conseguir, pero imprescindibles para componer cabalmente la obra que se pretendía, cabía ciertamente recabar informaciones - como apuntábamos - de religiosos y seglares que andaban por las partes de Oriente, pero también de otros sujetos que en Flandes o en Castilla podían conseguir noticias o conservar papeles. El propio Fr. João servía de correspondiente a su interlocutor, haciéndole llegar cartas y otros escritos que podían servir para sus propósitos memorísticos, e incluso dándole noticias sobre determinados lugares en los que cabía encontrar nuevos documentos relativos a la Orden. Así, al tiempo que le indicaba haber recibido un Oficio atribuido a San Simon Stock, trasladado de un impreso de 1580, le informaba que, por vía de un religioso trinitario venido de Inglaterra, había sabido que en la biblioteca del soberano inglés había "coças estupendas de nuestra sagrada religión" y señalaba la conveniencia de hacer las diligencias necesarias para contactar con algunos de los carmelitas que andaban por allá "disfraçados" para que averiguasen "lo antigo y moderno que nos pueda ser bueno para la historia general".22

Trazado el mapa de los lugares a los que se debía acudir en busca de documentos y escritos, la movilización de toda suerte de religiosos, personas graves o deudos del propio cronista no obedecía apenas a la necesidad de salvar una distancia física que, en ocasiones, resultaba de otro modo infranqueable. A veces, era asimismo el modo de vencer resistencias y acceder a determinados papeles cuyos custodios guardaban celosamente, tratando de sustraerlos a la mirada - y la copia - de quienes podían usarlos con fines menos claros. Jaboatão inscribió su peregrinaje por los conventos brasileños en el marco de la visita canónica que entonces realizó el secretario del provincial, para, de ese modo, tener mayor capacidad de "ver os seus Arquivos, revolver papeis, e esquadrinhar noticias" (Jaboatão, 1761, Antiloquio, preliminares sin paginar). El propio Fr. João de Cristo se lamentaba en su misiva de las dificultades que

22 Ibidem. 
siempre encerraba el lograr papeles de sus correligionarios de Italia, para lo cual señalaba la necesidad de recurrir a cardenales amigos y personas graves, a los que no se pudiese negar el "ver tal o tal relación", de modo que, "mostrada, hazerla trasladar de secreto, y leidas unas ir sacando otras".23

\section{El religioso participaba en ocasiones de una singular república literaria de dimensiones planetarias}

Este hurgar en pergaminos, libros y memorias por parte de correspondientes y cronistas se vio generalmente acompañado de concretas prácticas de escritura que, asociadas a las formas propias del quehacer erudito, exigían del religioso un minucioso trabajo de elaboración de notas y minutas, de composición de listas, de traslado de enteros documentos o, simplemente, de realización de copias de mano que reproducían pasajes extraídos de los textos y documentos consultados, reutilizados así más tarde — de forma literal, amplificados o sumariados - en la composición de la narración histórica. En cierto modo, el cronista podía crear con todos los materiales que iba reuniendo una especie de "archivo" propio, de particular acervo de copias manuscritas de documentos, inventarios, memorias. Como veíamos, Fr. Jerónimo de Belém no dudó en ordenar, numerándolas, las varias historias y relaciones que lo habían precedido. Entre ellas, los dos volúmenes atribuidos a Fr. Daniel dos Reis se configuraban además a modo de grandes cartapacios en los que, junto a los trechos del relato de Reis, alguien había incorporado las relaciones de los varios conventos de la provincia (Setúbal, Torres Vedras, Azores etc.), enviadas desde 1738 al entonces cronista, Fr. João de Nossa Senhora. ${ }^{24}$

$\mathrm{Al}$ margen de las rutinas que generaba el reunir y ordenar traslados de bulas, cartas regias, registros notariales, listados de religiosos, etc., la producción memorística que, manuscrita, había circulado en el seno de las congregaciones franciscanas, habría de tener un peso relativamente importante en la elaboración de las crónicas de los siglos XVII y XVIII. A menudo, los religiosos hacían alusión en los preámbulos de sus escritos a algunos de esos textos de mano que habían empleado para la composición de su historia. António da Piedade, por ejemplo, no dejó de evocar - aunque deslizando algunas críticas - los que habían elaborado quienes le habían precedido en la tarea de escribir la crónica de la provincia de Arrábida, refiriendo así el memorial de João das Chagas, los volúmenes de André de São Paulo y los cuadernos que bajo el nombre de Chronica había compuesto Luís da Ascensão a mediados del siglo XVII, con la intención - al final frustrada — de darlos a estampa (Piedade, 1728, Prologo ao Leytor, preliminares sin paginar). Más elocuente y prolijo era, una

23 Ibidem

${ }^{24}$ ANTT. Daniel dos Reis. Memorias da Santa Prouincia dos Algarues da Ordem Serafica. Anno de 1746. Livraria, mss. 1911-1912 
vez más, Fr. Manuel da Esperança que, junto a las obras de Marcos de Lisboa, Wading y Gonzaga, afirmaba haberse servido de otros muchos impresos y de no pocos manuscritos, entre los que señalaba tres catálogos de los obispos de Coimbra, Guarda y Viseu, algunas crónicas de los monarcas portugueses, distintos memoriales de las provincias de Arrábida, Piedade y los Algarves, varios escritos de los franciscanos de la India, el tratado titulado Monarchia serafica, compuesto por Fr. Paulo de São Pedro, así como diversas relaciones de personas y casas particulares, «feitas hũas por Autores timoratos: outras por autoridade pública» (Esperança, 1656-1666, preliminares sin foliar).

Las crónicas y memoriales manuscritos, por tanto, no sólo constituyeron un soporte recurrente de inscripción y difusión de la memoria franciscana, sino que fueron además piezas fundamentales en la composición de otros textos de carácter histórico que se dieron a impresión o que, por el contrario, acabaron, como aquéllos, circulando en copias de mano y dejando abierto el terreno - una vez más - a nuevas escrituras. En ocasiones, la propia elaboración de sucesivos memoriales manuscritos llegó a favorecer una especie de escritura por acumulación, en la que cada texto que se elaboraba de nuevo venía en la práctica a reproducir en su estructura y contenidos el anterior, añadiendo apenas aquellas noticias e informaciones dignas de mención que el correr de los tiempos había generado. Los volúmenes de carácter histórico o cronístico que, como apuntábamos, se realizaron en el seno de la provincia de los Algarves a lo largo del siglo XVII - reunidos y ordenados más tarde por Jerónimo de Belém - son, en buena medida, expresión elocuente de esa forma de composición de las crónicas. No obstante, la pauta a la hora de utilizar y reutilizar otros textos en la elaboración de las crónicas a menudo pasó por lógicas diferentes, en las que, siguiendo los cánones retóricos al uso en la composición de éste y otros géneros, la incorporación de las informaciones tomadas de distintos escritos podía asentar en la copia ad litteram de un determinado documento o testimonio, pero, a menudo, suponía la reelaboración de relaciones y narrativas, que se compendiaban o se desarrollaban en lo que no era ya sino un texto diferente, a pesar de que su 'novedad' fuese relativa (Grafton, 2001; Castillo Gómez, 2001-2002, Nakládalová, 2013).

Más allá de los pliegos, pergaminos, cartapacios, códices manuscritos y volúmenes impresos que se emplearon en la elaboración de las crónicas, y al margen de los usos que de ellos cabía hacer en cada ocasión, hubo asimismo una memoria viva que no dejó de constituir una fuente recurrente de información de la que se sirvieron los religiosos franciscanos. En una época que se ha definido como esencialmente oral y en la que, de hecho, la oralidad desempeñó un papel muy relevante en las prácticas culturales de letrados e iletrados (Bouza, 2003; Frenk, 1997; Egido, 2003; Daher, 2016), que un cronista hiciese uso de tales recursos no revestía carácter extraordinario alguno, ni menoscababa el crédito de su escrito. En realidad, la mayoría de los historiadores franciscanos del periodo - desde Manuel da Esperança, a Manuel de Monforte, António da Piedade o Jerónimo de Belém - refirió el uso que, junto a las evidencias 
escritas, había hecho de este tipo de noticias y tradiciones orales, acudiendo a menudo a los testimonios que de viva voz ofrecían los más ancianos de la congregación y, en particular, a las noticias que podían dar de aquellos hermanos de reputada virtud que habían fallecido sin dejar más memoria que la que conservaban quienes los habían tratado.

\section{Los religiosos hacian alusión en los preámbulos de sus escritos a algunos de esos textos de mano que habian empleado para la composición de su historia}

En este sentido, la edad y las buenas partes del religioso servían como garantes de veracidad en torno a unas historias que, en general, buscaban la edificación y la articulación narrativa de modelos ejemplares de vida y actuación religiosa, paliando en parte el vacío relativo que los cronistas franciscanos portugueses dijeron encontrar a la hora de acudir a las vidas escritas de aquellos varones de la Orden que se habían significado por sus virtudes. Jerónimo de Belém, no obstante los numerosos archivos conventuales que había visitado, notaba en el Prólogo de su crónica la falta que, en los papeles consultados, había de "individuaes noticias dos Varões insignes em virtudes". Lo achacaba principalmente a que, en los primeros tiempos de la Orden, "cuidava-se mais em obrar, do que em escrever", por lo que la mayoría de aquellos religiosos, fiados apenas de su propia memoria, acabaron por no dejar testimonio de sus virtudes y talentos para conocimiento y ejemplo de futuras generaciones (Belém, 1750-1758, t. I, preliminares sin paginar). Entre los manuscritos que utilizó, sin embargo, figuraba un cuaderno de reducidas dimensiones y con apenas un puñado de páginas, en el que otro religioso anónimo había registrado a finales del siglo XVII noticias sobre varios hermanos vinculados a los conventos de la provincia. ${ }^{25}$ El memorial, que Belém identificó como Caderno pequeno, no deja de ser expresivo del papel que pudo llegar a desempeñar una memoria oral de naturaleza edificante y ejemplarizante en el seno de las comunidades franciscanas portuguesas de la época, y de cómo ésta podía llegar a participar en la propia construcción de la memoria escrita. En efecto, numerosos comentarios a lo largo del opúsculo dejan entrever la naturaleza oral sobre la que asentaban las informaciones que en él se recogían. Su título hacía ya mención a que muchas de ellas no eran sino historias "oídas" a personas de crédito, pero la propia narración se salpicaba de acotaciones que, en idéntico sentido, aludían a lo que otros habían contado y a lo que de otros se había escuchado. Así, la fama que rodeaba la figura de Fr. Pedro dos Mártires, religioso del convento de Xabregas, era, como se decía, "opinião que achei

${ }^{25}$ ANTT. Memoria de alguns Religiozos de s.ta uida que morrerao nesta pro[uincila do Algarues, da qual eu sou indigno filho, das quaes ouui a pessoas dignas de credito. Anno 1679. Livraria, ms. 634. 
tinhão todos os que o conhecerão", del mismo modo que el episodio extraordinario que acompañó el tránsito a la otra vida de un hermano del convento de Beja, se afirmaba ser caso que "ouvi por uezes ao m[ui]to Rdo. Pe. fr. Fr[ancis] co de S[ão] D[oming]o". ${ }^{26}$ Las noticias, en ocasiones, combinaban la memoria personal de quien ahora escribía y el testimonio de otros religiosos, como en el caso de Fr. Francisco de Santa Úrsula, de Vila Viçosa, o de Fr. António do Amparo, sacerdote y hermano de ejemplar conducta, entregado en vida a la obediencia, la pobreza, el silencio y la oración. Del conjunto de virtudes que lo habían adornado - como advertía al final del relato su autor - no sólo era él mismo "testemunha de uisão e experiencia", sino que, además, era algo que "desião os mais religiosos obraua em os conu[en]tos aonde auia morado". ${ }^{27}$

La aparente penuria de relatos escritos con vidas de religiosos que, de modo sistemático, señalaban los cronistas franciscanos y la persistencia de una memoria que circulaba mediante el recurso a lo oral, contrastaría con las abundantes noticias que, a través de escritos de mano y de algunos impresos, daban cuenta de la vida y cualidades de un sinfín de religiosas. Por detrás, había prácticas de escritura diferenciadas. Huelga recordar que la producción y el consumo de memorias de conventos y, sobre todo, de textos de carácter 'biográfico' y 'autobiográfico' florecieron de modo exponencial en el interior de los claustros femeninos desde mediados del siglo XVI y a lo largo de toda la época moderna. Su elaboración se vio a menudo alentada y orientada por confesores y directores espirituales, que animaban así a las monjas de mayores cualidades a tomar la pluma y escribir sus propias vidas o las de otras hermanas de probadas virtudes (Poutrin, 1995; Lavrin \& Loreto, 2002; Lowe, 2003; Bellini, 2007; Bellini \& Pacheco, 2009; Zarri \& Baranda Leturio, 2011). Bien en cierto que la escritura de estas religiosas asentaba a menudo sobre procedimientos característicos precisamente - de una cultura oral, configurando textos destinados a la lectura en voz alta; una escritura más "oral" que, sin duda, se diferenciaba de formas más propias de una cultura letrada, sobre la que, en general, se conformaba la escritura memorística de los religiosos (Bellini, 2010), incluso cuando recurría a testimonios vivos. No obstante, el empeño que las clarisas mostraron en los varios contextos portugueses - al igual que en otras latitudes - a la hora de cultivar este género de escritos - de elaborar innumerables vidas de religiosas - marcaría asimismo una distinción con respecto a la aparente escasez de memorias en torno a los religiosos. ${ }^{28}$ Es más, esta disparidad no dejaría de trasladarse a las historias y memoriales de algunas provincias portuguesas de la Orden, donde los relatos y episodios relativos a las monjas de vida ejemplar acabaron recibiendo, frente a los religiosos, una atención mucho más extensa y detallada, fruto, sin duda, del mayor volumen de narrativas disponibles. ${ }^{29}$

${ }^{26}$ Ibidem, f. $1 \mathrm{v}$ y $6 \mathrm{v}-7 \mathrm{v}$.

${ }^{27}$ Ibidem, f. 11v-13v.

28 Para el caso de las religiosas agustinas en el contexto de la India portuguesa, veáse Gonçalves (2015)

${ }^{29}$ Véase, por ejemplo, ANTT. Rodrigo de São Tiago. Memorial da Santa Prova dos Algarves da Ordem Serafica [1616]. OFM. Prov. Algarves. Provincia, liv. 22, passim. 
Más allá de tales consideraciones, parece indiscutible el papel que, de un modo o de otro, acabó desepeñando la oralidad en la construcción de la memoria franciscana aún en una centuria como la de 1700, en la que, como se ha señalado, los frailes menores no sólo aumentarían su presencia en instituciones y círculos eruditos, tanto en Portugal como en los espacios imperiales, como ganarían visibilidad tipográfica, desarrollando además una considerable inversión en su propia memoria que se tradujo en un número importante de crónicas e historias impresas. Los escritos de mano, no obstante, continuaron teniendo una presenciaesencial en la producción cronística y en toda una serie de rutinas eruditas que acompañaron la propia elaboración de los textos memorísticos. La búsqueda y acumulacion de papeles que sirviesen de base a la composición de nuevas cronicas no sólo conllevó el "visitar" los lugares donde aquellos se guardaban, movilizando incluso extensas redes de correspondientes, como supuso el traslado en copias ad vivum de toda suerte de documentos y testimonios, además del recurso a un acervo - en ocasiones, extenso - de memoriales e historias anteriores que inscribían al cronista en una suerte de genealogía textual. En buena medida, ese acervo memorístico franciscano se construyó desde finales del siglo XVI y a lo largo del siglo XVII mediante una abundante producción que, en el reino y en los contextos coloniales, corrió esencialmente en forma manuscrita, configurando un universo escrito - erudito - que, a pesar de su menor fortuna editorial, situaba al mundo franciscano lejos de la posición sublaterna a la que, en el campo de la cultura intelectual altomoderna, la historiografía tradicionalmente lo ha relegado.

El presente trabajo se ha realizado al abrigo del proyecto de investigación Imperios de papel: textos, cultura escrita y religiosos en la configuración del Imperio portugués en la

Edad Moderna (1580-1668) - HAR2014-52693-P. Ministerio de Economía y Competitividad (España). Agradezco a Fernando Bouza la lectura del presente texto y sus generosos comentarios. 


\section{Referencias bibliográficas}

ALMEIDA, Marcos Antônio de. "L'Orbe Serafico, Novo Brasilico": Jaboatão et les franciscains à Pernambouc au XVIIIe siècle. (Tesis Doctoral en Historia), París. EHESS, 2012.

AMOR DE DEUS, Martinho do. Escola de penitencia, caminho da perfeição, estrada segura para a vida eterna. Chronica da Santa Provincia de S. Antonio da Regular, e Estreita Observancia da Ordem do Serafico Patriarca S. Francisco. Lisboa: Antonio Pedroso Galrão, 1740.

ANDRETTA, Stefano. La "realtà" ibérica nelle opere di Giovanni Pietro Maffei e Giovanni Botero. In: A Companhia de Jesus na Península Ibérica nos sécs. XVI e XVII: espiritualidade e cultura. Oporto: CIUHE-UP, 2004. v. 2, p. 522-531.

ATIENZA, Ángela (Ed.). Iglesia memorable. Crónicas, historias, escritos... a mayor gloria: siglos XVI-XVIII. Madrid: Sílex, 2012.

BARBOSA MACHADO, Diogo. Bibliotheca lusitana. Lisboa: António Isidoro da Fonseca, 1741 (t. I); Lisboa: Inácio Rodrigues, 1747 (t. II); Lisboa: Ignacio Rodrigues, 1752 (t. III); Lisboa: Francisco Luís Ameno, 1767 (t. IV).

BELÉM, Jerónimo de (OFM). Chronica Serafica da Santa Provincia dos Algarves, da Regular Observancia do Nosso Serafico Padre S. Francisco. Lisboa: Ignacio Rodrigues, 1750 (t. I); Lisboa: Mosteiro de S. Vicente de Fora, 1753 (t. II); Lisboa: Mosteiro de S. Vicente de Fora, 1755 (t. III); Lisboa: Mosteiro de S. Vicente de Fora, 1758 (t. IV).

BELLINI, Lígia. Vida monástica e práticas da escrita entre mulheres em Portugal no Antigo Regime. Campus Social, Lisboa, v. 3-4, p. 209-218, 2007.

. Cultura escrita, oralidade e gênero em conventos portugueses (séculos XVII e XVIII).

Tempo, Rio de Janeiro, v. 29, p. 211-233, 2010.

; PACHECO, Moreno Laborda. Experiência e ideais de vida religiosa em mosteiros portugueses clarianos, nos séculos XVII e XVIII. Revista de História, São Paulo, v. 160, p. 147-167, 2009. BETRÁN, José Luis (Ed.). La Compañia de Jesús y su proyección mediática en el mundo hispánico durante la Edad Moderna. Madrid: Sílex, 2010.

BIEDERMANN, Zoltán. El espacio sujeto al tiempo en la cronística franciscana: una relectura de la conquista espiritual de Oriente de Fr. Paulo da Trindade. In: PALOMO, Federico (Ed.). La memoria del mundo: clero, erudición y cultura escrita en el mundo ibérico (siglos XVI-XVIII). Madrid: Universidad Complutense, 2014. p. 221-242.

BOUZA, Fernando. Comunicación, conocimiento y memoria en la España de los siglos XVI y XVII. Salamanca: Semyr, 1999.

. Corre manuscrito: una historia cultural del Siglo de Oro. Madrid: Marcial Pons, 2001.

Palabra e imagen en la corte: cultura oral y visual de la nobleza en el Siglo de Oro.

Madrid: Abada, 2003.

BROCKEY, Liam. An imperial republic: Manuel Severim de Faria surveys the Globe, 1608-1655. In: BERBARA, Maria; ENENKEL, Karl (Ed.). Portuguese humanism and the Republic of Letters. Leiden: Brill, 2012, p. 265-288.

BUESCU, Ana Isabel. Livrarias conventuais no Oriente português: os casos de Santo António de Taná e de Santa Cruz dos Milagres (Goa). Anais de História d'Além Mar, Lisboa, v. 2, p. 33-46, 2001. BUFFON, Giuseppe. Storia dell'Ordine francescano: problemi e prospettive di metodo. Roma: Edizioni di Storia e Letteratura, 2013.

. Sulle tracce di una storia omessa: storiografia moderna e contemporanea dell'Ordine francescano. Grottaferrata: Frati Editori di Quaracchi, 2011.

CABATON, A. Catalogue sommaire des manuscrits indiens, indo-chinois et malayo-polynésiens de la Bibliothèque Nationale. París: Ernest Leroux Éditeur, 1912.

CAMPOS, Maria Fernanda. Para se achar facilmente o que se busca: bibliotecas, catálogos e leitores no ambiente religioso, século XVIII. Casal de Cambra: Caleidoscópio, 2015.

CARVALHO, José Adriano de Freitas (Ed.). Da memória dos livros às bibliotecas da memória. I: inventário da livraria de Santo António de Caminha. Oporto: CIUHE, 1998.

(Ed.). Quando os frades faziam história: de Marcos de Lisboa a Simão de Vasconcellos.

Oporto: CIUHE, 2001a. 
. As Crónicas da Ordem dos Frades Menores de Fr. Marcos de Lisboa ou a história de um triunfo anunciado. In: (Ed.). Quando os frades faziam história: de Marcos de Lisboa a Simão de Vasconcellos. Oporto: CIUHE, 2001b. p. 9-81.

(Ed.). Da memória dos livros às bibliotecas da memória. II: inventário da livraria de Santo António de Ponte de Lima. Oporto: CIUHE, 2005.

CASTILLO GÓMEZ, Antonio. "No pasando por ello como gato sobre brasas": leer y anotar en la España del Siglo de Oro. Leituras. Revista da Biblioteca Nacional, Lisboa, 3. série, v. 9-10, p. 99-121, 2001-2002.

CHAGAS, António das (OFM). Obras espiritvaes. Lisboa: Miguel Deslandes, 1688. 2 v.

(OFM). Sermoens genvinos e praticas espiritvaes. Lisboa: Miguel Deslandes, 1690.

CHINCHILLA, Perla; ROMANO Antonella (Ed.). Escrituras de la modernidad: los jesuitas entre cultura retórica y cultura científica. México: Universidad Iberoamericana, 2008.

EGIDO, Aurora. La voz de las letras en el Siglo de Oro. Madrid: Abada, 2003.

DAHER, Andrea. L'oralité perdue: essais d'histoire des pratiques lettrées (Brésil, XVIe-XIXe siècle). París: Classiques Garnier, 2016.

ESPERANÇA, Manuel da. Historia serafica da Ordem dos Frades Menores de S. Francisco na provincia de Portugal. Lisboa: Oficina Craesbeeckiana, 1656 (t. I); Lisboa: António Craesbeeck de Melo, 1666 (t. II).

FABRE, Pierre-Antoine; ROMANO, Antonella (Ed.). Les jésuites dans le monde moderne: nouvelles approches. Revue de Synthèse, París, v. 120, n. 2-3, 1999. Dossier monográfico.

FARDILHA, Luís Sá. Uma introdução à História seraphica... na provincia de Portugal. In: CARVALHO, José Adriano de Freitas (Ed.). Quando os frades faziam história: de Marcos de Lisboa a Simão de Vasconcellos. Porto: CIUHE, 2001. p. 103-119.

FARIA, Patrícia Souza de. Literatura espiritual e história dos franciscanos no Oriente português: a escrita de Jacinto de Deus, um frade nascido na Cidade do Nome de Deus de Macau. Locus: Revista de História, Juíz de Fora, v. 17/1, p. 217-236, 2011.

FRENK, Margit. Entre la voz y el silencio. Alcalá de Henares: Biblioteca de Estudios Cervantinos, 1997.

GIARD, Luce (Ed.). Les jésuites à la Renaissance: système éducatif et production du savoir. París: PUF, 1995.

GONÇALVES, Margareth de Almeida. Entre "heroicas virtudes" e a história: a escrita de frei Agostinho de Santa Maria e a sacralização da vida conventual de mulheres na Ásia portuguesa no limiar do século. In: _ _ _ GANDELMAN, Luciana; FARIA, Patricia Souza de (Org.). Religião e linguagem nos mundos ibéricos: identidades, vínculos sociais e instituições. Rio de Janeiro: Edur, 2015. v. 1, p. 17-48.

GRAFTON, Anthony. El lector humanista. In: CAVALLO, Guglielmo; CHARTIER, Roger (Ed.). Historia de la lectura en el mundo occidental. Madrid: Taurus, 2001. p. 319-371.

HERNÁNDEZ, Bernat. Tesoros verdaderos de las Indias... Religión, criollismo y república literaria en fray Juan Meléndez, OP (1681-1682). In: ATIENZA, Ángela (Ed.). Iglesia memorable. Crónicas, historias, escritos... a mayor gloria: siglos XVI-XVIII. Madrid: Sílex, 2013. p. 251-273.

ILHA, Manuel da. Narrativa da Custódia de Santo Antônio do Brasil (1584-1621). Petrópolis: Vozes, 1975.

JABOATÃO, António de Santa Maria. Orbe Serafico Novo Brasilico... Parte primeira da chronica dos frades menores da mais estreita, e regular obsevancia da provincia do Brasil. Lisboa: António Vicente da Sylva, 1761.

KANTOR, Íris. Esquecidos e renascidos: historiografia acadêmica luso-americana, 1724-1759. São Paulo: Hucitec, 2014.

LAVRIN, Asunción; LORETO, Rosalva (Ed.). Monjas y beatas: la escritura femenina en la espiritualidad barroca novohispana, siglos XVII y XVIII. Puebla: Universidad de las Américas, 2002. LOPES, Félix. Fontes narrativas e textos legais para a História da Ordem Franciscana em Portugal. In:_____ Colectânea de estudos de história e literatura. Lisboa: Academia Portuguesa de História, 1997. v. I, p. 1-269.

. Introdução. In: TRINDADE, Paulo da. Conquista Espiritual do Oriente. Lisboa: Centro de Estudos Históricos Ultramarinos, 1962. v. 1, p. VII-XXIII.

LOWE, K. J. P. Nun's chronicles and convent culture in Renaissance and Counter-Reformation Italy. Cambridge: Cambridge UP, 2003. 
MONFORTE, Manuel de. Chronica da provincia da Piedade, primeira Capucha de toda a Odem, \& regular observancia de nosso seraphico Padre S. Francisco. Lisboa: Miguel Deslandes, 1696. MONTCHER, Fabien. Archives and empire: scholarly archival practices, royal historiographers, and historical writing across the Iberian Empire (late $16^{\text {th }}$ and early $17^{\text {th }}$ century). Storia della Storiografia, Pisa-Roma, v. 68/2, p. 21-35, 2015.

NAKLÁDALOVÁ, Iveta. La lectura docta en la primera Edad Moderna (1450-1650). Madrid: Abada, 2013.

OLIVEIRA, Maria Lêda. A Historia do Brazil de Frei Vicente do Salvador: história e política no império português do século XVII. São Paulo: Odebrecht, 2008.

PALOMO, Federico. Corregir letras para unir espíritus: los jesuitas y la cartas edificantes en el siglo XVI. In: BOUZA, Fernando (Ed.). Cultura epistolar en la alta Edad Moderna: usos de la carta y de la correspondencia entre el manuscrito y el impreso. Madrid: Universidad Complutense, 2005. p. 57-81.

. Misioneros, libros y cultura escrita en Portugal y España durante el siglo XVII. In: CASTELNAU-L'ESTOILE, Charlotte et al. Missions d'évangélisation et circulation de savoirs, XVIe-XVIIIe siècle. Madrid: Casa de Velázquez, 2011. p. 131-150.

. Conexiones atlánticas: Fr. Apolinário da Conceição, la erudición religiosa y el mundo del impreso en Portugal y el Atlántico durante el siglo XVIII. In: (Ed.). La memoria del mundo: clero, erudición y cultura escrita en el mundo ibérico (siglos XVI-XVIII). Madrid: Universidad Complutense, 2014. p. 111-137.

. Ascetic tropics: franciscans, missionary knowledge and visions of empire in the Portuguese Atlantic at the turn of the eighteenth-century. Culture \& History, Madrid, v. 5/2, 2016. En prensa. PIEDADE, António da. Espelho de penitentes, e chronica da provincia de Santa Maria da Arrabida, da Regular, e mais estreita observancia, da Ordem do Serafico Patriarcha S. Francisco, no Instituto Capucho. Lisboa: Joseph Antonio da Sylva, 1728.

PONTES, Maria de Lurdes Belchior. Bibliografia de António da Fonseca Soares (Frei António das Chagas). Lisboa: Centro de Estudos Filológicos, 1950.

. Frei António das Chagas: um homem e um estilo do séc. XVII. Lisboa: Centro de Estudos Filológicos, 1955.

POUTRIN, Isabelle. Le voile et la plume: autobiographie et saintété féminine dans l'Espagne moderne. Madrid: Casa de Velázquez. 1995.

ROCHA Idílio. Catálogo da livraria do convento da Arrábida. Lisboa: Fundação Oriente, 1994. SANZ HERMIDA, Jacobo. La Tercera Parte de las Chrónicas de fray Marcos de Lisboa (1570) y los franciscanos de Salamanca. In: CARVALHO, José Adriano de Freitas (Ed.). Frei Marcos de Lisboa: cronista e bispo do Porto. Oporto: CIUHE-ICP, 2002. p. 253-274.

SOLEDADE, Fernando da. Historia serafica chronologica da Ordem de S. Francisco na provincia de Portugal. Lisboa: Manuel \& José Lopes Ferreira, 1705 (t. III); Lisboa: Manuel \& Joseph Lopes Ferreyra, 1709 (t. IV); Lisboa: Antonio Pedrozo Galram, 1721 (t. V).

WALTER, Jaime. Estudo. In: LISBOA, Cristóvão de. Historia dos animaes e arvores do Maranhão. Lisboa: CNCDP, 2000. p. 31-58 (1. ed.: Lisboa: Arquivo Histórico Ultramarino, 1967).

XAVIER, Ângela Barreto. Itinerários franciscanos na Índia seiscentista, e algunas questões de história e de método. Lusitânia Sacra, Lisboa, n. 18, p. 97-116, 2006. ICS, 2008.

A invenção de Goa: poder imperial e conversões culturais nos séculos XVI e XVII. Lisboa:

. Les bibliothèques virtuelles et réelles des franciscains en Inde au XVIIe siècle. In: CASTELNAU-L'ESTOILE, Charlotte de et al. (Ed.). Missions d'évangélisation et circulation des savoirs, XVIe-XVIIIe siècles. Madrid: Casa de Velázquez, 2011. p. 151-170.

. Fr. Miguel da Purificação, entre Madrid y Roma: relato del viaje a Europa de un franciscano portugués nacido en la India. In: PALOMO, Federico (Ed.). La memoria del mundo: clero, erudición y cultura escrita en el mundo ibérico (siglos XVI-XVIII). Madrid: Universidad Complutense, 2014. p. 87-110.

;ŽUPANOV, Ines G. Catholic orientalism: Portuguese empire, Indian knowledge (16th-18th centuries). Nueva Delhi: Oxford University Press, 2015.

ZARRI, Gabriella; BARANDA LETURIO, Nieves (Ed.). Memoria e comunità femminili: Spagna e Italia, secc. XV-XVII. Florencia: Firenze Univeristy Press-UNED, 2011. 